\title{
Los Goya de la Real Academia de la Historia: Análisis de documentación artística
}

\author{
Lara NEBREDA MARTÍN \\ Universidad Complutense de Madrid. Facultad de Ciencias de la Documentación \\ mlnebreda@pdi.ucm.es
}

Recibido: Mayo 2012

Aceptado: Julio 2012

Resumen: La principal fuente de información de una obra de arte es siempre la pieza en sí misma. Pero además existen unos documentos generados durante toda la vida de la obra, cuyo conocimiento apoya de manera innegable el desarrollo de cualquier investigación científica sobre un determinado objeto artístico. A partir del estudio de la documentación generada por cuatro retratos realizados por Goya, que actualmente se conservan en la Real Academia de la Historia, presentamos las tipologías documentales más habituales que generan las obras de arte y relacionamos su génesis con las etapas de la vida de la pieza. Asimismo exponemos la utilidad de controlar y conocer estos documentos realizando la reconstrucción historiográfica de cada uno de los retratos, con la intención de demostrar que la documentación en el Arte es una vía de investigación válida que reporta resultados y contribuye al desarrollo de otras disciplinas.

Palabras clave: Documentación, Arte, Historiografía, Francisco de Goya, Real Academia de la Historia.

\section{Goya in the Royal Academy of History: Analisys of art documentation}

\begin{abstract}
Abstract: The main source of information regarding an art piece is always the piece itself. But there is also specific documentation created during the existence of an art piece, whose analysis truly fosters the development of any scientific research on any specific work of art. Starting from the study of the documentation generated by four portraits painted by Goya, now preserved at the Royal Academy of History, we present the most common sorts of documents created by works of art and we link their origin to the period of existence of the piece. We also set out the advantages of controlling and understanding these dossiers through the documentary reconstruction of each portrait, aiming to prove that documentation in Art is an interesting research topic that offers some results and helps to the development of other disciplines.
\end{abstract}

Keywords: Documentation, Art, Historiography, Francisco de Goya, Royal Academy of History.

\section{INTRODUCCIÓN}

Las obras de arte son objetos que generan gran cantidad de información sobre el contexto en que fueron creadas y sobre su autor. Pero además, como pretendemos demostrar en esta investigación, originan un importante y variado 
volumen de documentación, cuyo conocimiento contribuye de manera sustancial al estudio científico de cada pieza.

Nuestro trabajo se basa en la recopilación y el análisis de los documentos producidos por los retratos de Carlos IV (1,37 x 1,10 m), María Luisa de Parma (1,52 x 1,11 m), Fray Juan Fernández de $\operatorname{Rojas}^{1}\left(0,77\right.$ x 0,55 m) y José de Vargas Ponce ${ }^{2}(1,04$ x 0,82 m), realizados por Francisco de Goya, que actualmente se conservan en la Real Academia de la Historia (en adelante R.A.H.). Pretendemos que esta investigación se centre en el aspecto documental, por este motivo, para cualquier consulta sobre la obra de Goya remitimos a las publicaciones de expertos investigadores como José Gudiol, José Camón Aznar, José Luis Morales o Pierre Gassier, así como al Catálogo de pinturas de la Real Academia de la Historia ${ }^{3}$.

En este artículo expondremos además la escasez de estudios científicos relativos a la documentación generada por el Arte e intentaremos demostrar que es una vía de investigación con características propias y tipologías documentales específicas, con la finalidad de revalorizar los documentos archivísticos de colecciones artísticas como instrumentos indispensables en la investigación de una obra de arte.

\section{METODOLOGÍA}

Durante la primera fase de esta investigación realizamos un proceso de recopilación de los documentos relativos a las obras de Goya. Efectuamos búsquedas en el Gabinete de Pintura de la R.A.H. ${ }^{4}$ y en la Biblioteca Virtual Miguel de Cervantes ${ }^{5}$, donde se encuentran digitalizados los fondos del Gabinete de Antigüedades y del Gabinete Numario de la R.A.H. También consultamos varios diplomatarios y colecciones de cartas de Goya ${ }^{6}$ y José de Vargas Ponce ${ }^{7}$, donde no hallamos nada referido a los retratos objeto de estudio de este trabajo.

${ }^{1}$ Fray Juan Fernández de Rojas (Colmenar de Oreja, Madrid, 1752 - Madrid, 1819), fraile agustino conocido por su obra literaria Crotalogía (1792).

${ }^{2}$ José de Vargas Ponce (Cádiz, 1760 - Madrid, 1821) marino, político, militar, escritor y director de la Real Academia de la Historia en dos ocasiones (30 de noviembre de $1804-27$ de noviembre de 1807 y 25 de febrero de 1805 - 29 de noviembre de 1816).

${ }^{3}$ GONZÁLEZ ZYMLA, Herbert; FRUTOS SASTRE, Leticia de; PÉREZ SÁNCHEZ, Alfonso E. Catálogo de pinturas de la Real Academia de la Historia. Madrid: R. A. H., 2003. 333 p.

${ }^{4}$ GONZÁLEZ ZYMLA, Herbert; FRUTOS SASTRE, Leticia de. Archivo de la colección de pintura y escultura de la Real Academia de la Historia: Catálogo e índices. Madrid: R. A. H., 2002. $118 \mathrm{p}$.

5 BIBLIOTECA VIRTUAL MIGUEL DE CERVANTES [en línea]. Catálogo. $<$ http://www.cervantesvirtual.com/> [Consulta: 2012-25-03].

${ }^{6}$ GOYA, Francisco de. Cartas a Martín Zapater. Mercedes Águeda, Xavier de Salas, ed. Madrid: Turner, 1982. 244 p.; GOYA, Francisco de. Diplomatario. Ángel Canellas López, ed. Zaragoza: Institución Fernando el Católico, 1981. 590 p.; y GOYA, Francisco de. Diplomatario: Addenda. Ángel Canellas López, ed. Zaragoza: Institución Fernando el Católico, 1991. 40 p. 
El segundo paso consistió en la transcripción de los documentos localizados, con la finalidad de crear un corpus documental cerrado que facilitase su consulta y estudio.

En el análisis de la documentación tratamos de crear una clasificación tipológica de los documentos y su relación con las distintas fases que pueden establecerse en la vida de una obra artística. Una vez reunida, transcrita y analizada la documentación, elaboramos una reconstrucción historiográfica de la vida de cada obra basándonos en la información que los documentos consultados nos han proporcionado.

\section{ESTADO DE LA CUESTIÓN}

El principal problema de este trabajo ha sido la falta de bibliografía relacionada con este tema específico, ya que la mayoría de las obras localizadas realmente son repertorios bibliográficos centrados en el $\mathrm{Arte}^{8}$. Las publicaciones consultadas sobre documentación en esta área tienen una clara perspectiva museística centrada en el control de los documentos de gestión que generan las piezas de las colecciones, pero no en los originados anteriormente. En Numismática y Arqueología sí se ha concedido una mayor importancia a la Documentación como disciplina auxiliar y se han desarrollando investigaciones basadas en la recopilación de documentos para reconstruir la historia de una pieza ${ }^{9}$. Conviene

${ }^{7}$ SEONE, Marqués de. "Correspondencia epistolar entre don José Vargas Ponce y don Juan Agustín Ceán Bermúdez durante los años 1803 a 1805, existente en los archivos de la Dirección de Hidrografía y de la Real Academia de Historia". Boletín de la Real Academia de la Historia. Julio-septiembre, 1905, tomo XLVII, cuadernos I-III, pp. 5-60 y FERNÁNDEZ DURO, Cesáreo. Correspondencia epistolar de D. José de Vargas Ponce y otros en materias de arte: Colegida por D. Cesáreo Fernández Duro y publicada por la Real Academia de Bellas Artes de San Fernando. Madrid: [s.n.], 1900. 347 p.

${ }^{8}$ GALLEGO LORENZO, Josefa. "Estado actual de los estudios bibliográficos sobre el arte en España". Scire: representación y organización del conocimiento. 2005, vol.11, no 1, pp. $65-$ 82. GARCÍA MELERO, Enrique. Aproximación a una bibliografia de la pintura española. Madrid: Fundación Española Universitaria, 1978. 1188 p. GARCÍA MELERO, E.; AZORÍN LÓPEZ, V.; SORLI ROJO, A. "Los repertorios bibliográficos españoles sobre las artes plásticas". Revista Española de Documentación Científica. 1990, vol. 13, nº 2. pp. 733-755.

${ }^{9}$ ALFARO ASINS, C.; OTERO MORÁN, P. y MARCOS ALONSO, C. "El Gabinete Numismático: 1711-1999". En: Tesoros del Gabinete Numismático. Las 100 mejores piezas del monetario del Museo Arqueológico Nacional. Madrid: Real Academia de la Historia, 1999. pp. 15-49; ALMAGRO-GORBEA, M.; MAIER ALLENDE, J. "La Real Academia de la Historia y la Arqueología española en el siglo XVIII". En: Congreso Internacional Iluminismo $e$ Ilustración. Le antichitá e $i$ suoi protagonisti in Spagna e in Italia nel XVIII secolo. Roma, 2004. pp. 1-27; ARCE, J. Historiografía de la Arqueología y la Historia Antigua en España (siglos XVIII-XX). Olmos, Ricardo (ed.). Madrid: Instituto de Conservación y Restauración de Bienes Culturales, 1991. 275 p.; CANTO GARCÍA, A.; MARTÍN ESCUDERO, F. El hallazgo de Belalcázar (Córdoba): nuevas aportaciones. Qurtuba. 2000, $\mathrm{n}^{\circ}$ 5. pp. 27-40; CANTO GARCÍA, A.; MARTÍN ESCUDERO, F.; VICO MONTEOLIVA, J. Monedas Visigodas. 
señalar que, precisamente por esta falta de estudios previos, al plantearnos esta investigación desconocíamos por completo qué volumen de documentación íbamos a localizar, así como las distintas tipologías y sus características propias.

La bibliografía consultada nos muestra que los distintos responsables culturales son conscientes de la necesidad de conservar y normalizar la documentación que genera la obra en el museo, pero no existe una reflexión sobre la importancia, utilidad y enriquecimiento que para la colección puede suponer el reunir y reconstruir documentalmente la vida del objeto artístico.

Los países pioneros en la gestión de la información documental en los museos han sido Estados Unidos con el Comité para la Documentación del Consejo Internacional de Museos (CIDOC del ICOM) y Gran Bretaña con la Asociación para la Documentación en los Museos (MDA). A principios de los años setenta se comenzó en los dos países anglosajones a utilizar el término Museum information and documentation (Información y documentación museográfica), que incluye la conservación y documentación de las obras artísticas y la información asociada a cada pieza ${ }^{10}$.

Catálogo del Gabinete de Antigüedades de la Real Academia de la Historia. Madrid: Real Academia de la Historia, 2002. 336 p.; CANTO GARCÍA, A.; RODRÍGUEZ CASANOVA, I. "Nuevos datos acerca de la inscripción califal atribuida al Castillo de Baños de la Encina (Jaén)". Arqueología y Territorio Medieval. 2006, n 13. pp. 57-66.; MAIER, J. "La Comisión de Antigüedades de la Real Academia de la Historia". $3^{\circ}$ Congresso de Arqueologia Peninsular. Vol 1. Arqueología peninsular. História, teoria e prática. Porto, 2000. pp. 213-236; "II Centenario de la Real Cédula de 1803. La Real Academia de la Historia y el inicio de la legislación sobre el Patrimonio Arqueológico y Monumental en España". Boletín de la Real Academia de la Historia. Madrid, 2003. pp. 439-473; MARTÍN ESCUDERO, F. "Sobre el hallazgo de dinares del Hospital Militar de Zaragoza (1858)". Actas XI Congreso Nacional de Numismática. Zaragoza 16-19 de Octubre de 2002. Zaragoza, 2003. pp. 257-268 y "El primer proyecto de publicación de un catálogo de moneda andalusí en España: Discurso y Tablas de Medallas Árabes de Miguel de Casiri”. Documenta \& Instrumenta, 8. Madrid, 2010. pp. 145180; MARTÍN ESCUDERO, F.; CEPAS PALANCA, A, y CANTO GARCÍA, A. Archivo del Gabinete Numario. Catálogo e índices. Serie Documentación de la Real Academia de la Historia. Madrid, 2004. 464 p.; MARTÍNEZ NÚÑEZ, M. A.; RODRÍGUEZ CASANOVA, I. y CANTO GARCÍA, A. Epigrafía árabe. Catálogo del Gabinete de Antigüedades. Real Academia de la Historia. Madrid, 2007. 397 p.; MORA, G. Historias de Mármol. La Arqueología clásica española en el siglo XVIII. Anejos de Archivo Español de Arqueología, XVIII. Madrid, 1998. 164 p.; "Origen de los estudios numismáticos en España: el manuscrito perdido de Felipe de Guevara y otros tratados del siglo XVI". XIII Congreso Internacional de Numismática. Madrid-2003. Actas. Tomo I. Madrid, 2005. pp. 77-83 y "Coleccionistas españoles en Italia. El monetario de Dámaso Puertas, médico del XIV duque de Alba". Arqueología, Coleccionismo y Antigüedad. España e Italia en el siglo XIX. Sevilla, 2007. pp. 435-458; SALAS ÁLVAREZ, J.A. La arqueología en Andalucía durante la Ilustración (17361808). Málaga-Sevilla, 2010. 377p.

${ }^{10}$ MARÍN TORRES, María Teresa. "La documentación museográfica en el Reino Unido: tendencias actuales". Imafronte. 1998-1999, n 14. pp. 141-154. 
En Latinoamérica, Colombia ${ }^{11}$ y Chile también han trabajado en el área de la normalización documental en museos, colaborando incluso con el Getty Museum de Los Ángeles ${ }^{12}$.

En 1996 la Comisión de Normalización Documental de Museos de España publicó Normalización documental de museos. Esta obra está centrada en el estudio de la documentación que se produce en la gestión de colecciones museísticas, en la normalización de los procesos documentales, en la creación de lenguajes controlados y aplicaciones informáticas especializadas. Pero además, contempla la existencia de unos fondos documentales generados específicamente en torno a la obra que se constituyen:

"Como fuentes de investigación, que pueden haber surgido con muy diferentes finalidades y en estrecha relación con los fondos o la especialidad científica del museo, como testamentos, correspondencia personal y científica de personajes relacionados con la historia o las colecciones del museo, diarios de trabajos de campo, memorias de excavación, inventarios de colecciones particulares, etc. ${ }^{13 "}$.

A estos documentos los denomina primarios. También reconoce la existencia de otra tipología a la que califica de documentos secundarios e identifica con el material de carácter científico y de investigación relacionado con la obra o la temática específica del museo. Estos documentos no son material propio del archivo administrativo, sino que constituyen un fondo independiente que debe ser tratado como tal.

Por lo demás, esta obra se centra en la normalización, sin estudiar con más profundidad las implicaciones que la existencia de esos documentos primarios puede tener para la colección, la investigación de la pieza y la reconstrucción de su historia.

El enfoque tradicional de la investigación de la documentación relacionada con el Arte en España, se ha centrado en la realización de repertorios bibliográficos especializados que recogen fuentes de información de distintos aspectos del Arte. Este principio está cambiando y así, en el $V$ Encuentro de Centros de Documentación de Arte Contemporáneo: Innovación y nuevas estrategias de investigación y difusión del patrimonio documental artístico, celebrado en Artium Centro-Museo Vasco de Arte Contemporáneo los días 3 y 4 de noviembre de 2010, se presentaron las iniciativas más

${ }^{11}$ RED NACIONAL DE MUSEOS. Guía para el inventario, catalogación y documentación de colecciones de museos. Bogotá: Ministerio de Cultura: Museo Nacional de Colombia, 2004. 104 p.

${ }^{12}$ Manual de registro y documentación de bienes culturales. Lina Ángel Vega, ed. Santiago de Chile: CDPB, 2008. 142 p.

${ }^{13}$ COMISIÓN DE NORMALIZACIÓN DOCUMENTAL DE MUSEOS. Normalización documental de museos: elementos para una aplicación informática de gestión museográfica. Madrid: Ministerio de Educación y Cultura. Secretaría General Técnica, 1998. p. 121. 
destacadas de varios centros de documentación de instituciones artísticas. Debemos destacar la labor que está realizando el Centro de Documentación de las Artes Escénicas de Andalucía con su proyecto de recopilación y custodia de materiales diversos (carteles, escenografias, bocetos de vestuario, recortes de prensa, fotografias, vídeos de representaciones...) que contribuyen a reconstruir la historia de la danza y el teatro en la comunidad autónoma ${ }^{14}$. El Servicio de Bibliotecas de la Fundación Juan March también ha optado por crear unos fondos compuestos por todos aquellos elementos (correspondencia, bocetos, carteles, partituras, críticas de prensa, estudios biográficos de compositores y dramaturgos, grabaciones sonoras, programas de mano, fotografías...) que permitan crear una memoria de la música y el teatro contemporáneo español, , entre ellos el de Joaquín Turina estudiado por Olivera Zaldua ${ }^{15}$.

Javier Docampo, como jefe del área de Biblioteca, Archivo y Documentación del Museo del Prado, expuso en este mismo Congreso que su equipo está empezando a realizar estudios sobre la documentación generada por cada obra de arte y la importancia que su conocimiento puede tener para la investigación de la pieza. Desde esta institución, además, se está trabajando en la valoración del fondo antiguo de la Biblioteca como material susceptible de ser mostrado al público en exposiciones temporales como fue el caso de Bibliotheca Artis: Tesoros de la Biblioteca del Museo del Prado ${ }^{16}$.

En las I Jornadas de Bibliotecas de Museos: nuevos medios y nuevos públicos, organizadas por BIMUS ${ }^{17}$ entre el 28 y el 30 de noviembre de 2011, se expuso que los museos de arte contemporáneo sí son conscientes de la necesidad de conservar la documentación que se genera en torno a la obra de arte, ya que a menudo la obra física tiende a desaparecer. Un ejemplo claro son las performance: el hecho artístico se produce en un determinado momento, lo que perdura del mismo son las grabaciones o el material empleado para desarrollarlas, es decir, la documentación. Además, muchos artistas contemporáneos crean conscientemente su propio archivo privado, en el que no solo incluyen documentos administrativos, comerciales o económicos, sino que dedican un gran esfuerzo para reunir

${ }^{14}$ JUNTA DE ANDALUCÍA. Centro de Documentación de las Artes Escénicas de Andalucía [en línea]. $<$ http://www.juntadeandalucia.es/cultura/cdaea/ $>$ [Consulta: 25 de marzo de 2012].

${ }^{15}$ FUNDACIÓN JUAN MARCH. Biblioteca. [en línea]. <http://www.march.es/bibliotecas/> [Consulta: 26 de marzo de 2012]; OLIVERA ZALDUA, María. La colección fotográfica de Joaquín Turina. Madrid: Editorial Académica Española, 2011.345 p.

${ }^{16}$ Exposición celebrada entre el 5 de octubre de 2010 y el 30 de enero de 2011, dirigida por Javier Docampo, jefe del área de Biblioteca, Archivo y Documentación del Museo del Prado. Museo Nacional del Prado. Bibliotheca Artis: Tesoros de la biblioteca del Museo del Prado. [en línea].

$<$ http://www.museodelprado.es/exposiciones/info/en-el-museo/bibliotheca-artis-tesoros-dela-biblioteca/> [Consulta: 2012-01-17].

${ }^{17}$ BIMUS: Red de Bibliotecas de Museos dependientes del Ministerio de Cultura, actual Ministerio de Educación, Cultura y Deporte. 
materiales diversos que son susceptibles de ser utilizados en sus creaciones o que pueden servir de inspiración, convirtiéndose en fuentes de investigación de un valor incalculable. Por este motivo, desde los Centros de Documentación del MACBA $^{18}$ y del MUSAC ${ }^{19}$ se trabaja en la adquisición de archivos privados de artistas contemporáneos y sobre todo en su divulgación a través del fomento de la investigación y el empleo de las nuevas tecnologías.

A nivel internacional, la Biblioteca Kandinsky del Centro Pompidou trabaja en la modernización de sus servicios, creando plataformas de difusión de artistas noveles, pero principalmente invirtiendo en la adquisición de material variado sobre artistas contemporáneos y sus obras, e incluyendo estos documentos como parte valiosa de la exposición museística de las colecciones de este centro parisino. Destaca también la labor de la Biblioteca del MoMA de Nueva York, cuyo principal objetivo es llegar a ser un referente mundial en la investigación del arte contemporáneo latinoamericano, por este motivo, destina gran parte de su presupuesto a la adquisición de documentación relacionada y su difusión mediante exposiciones, estudios, traducciones, realización de repertorios bibliográficos...

La arquitectura es otro campo en el que los archivos son un instrumento muy valorado, ya que la construcción de un edificio supone la realización de un proyecto previo que genera una gran cantidad de documentación. No es extraño en este mundo que los bocetos o maquetas alcancen altas tasaciones económicas o importantes valores artísticos. Conscientes de ello, son muchos los países que cuentan con una organización destinada a reunir estos fondos, incluso si se encuentran en manos privadas, e impedir así su dispersión o pérdida. Destaca en este sentido la labor del Centre Canadien d'Architecture de Montreal; la Avery Library: Drawings and archives Collection de la Universidad de Columbia o L'Associazione nazionale Archivi di Architettura contemporanea, cuya sede se encuentra en la ciudad italiana de Venecia. En España podemos destacar la labor del Colegio Oficial de Arquitectos de Madrid que mediante la recopilación y estudio de sus fondos archivísticos, pretende documentar el patrimonio arquitectónico de esta Comunidad Autónoma ${ }^{20}$.

Andrés Gutiérrez Usillos publicó en junio de 2010 Museología y documentación: criterios para la definición de un proyecto de documentación en museos, donde contempla la necesidad de reunir toda la documentación que genera una obra de arte durante su vida, tal y como planteamos nosotros en este trabajo ${ }^{21}$.

${ }^{18}$ MACBA: Museo de Arte Contemporáneo de Barcelona.

${ }^{19}$ MUSAC: Museo de Arte Contemporáneo de Castilla y León.

${ }^{20}$ BLANCO, Manuel. "Los archivos de arquitectura". Archivos de arquitectura: Documentos para el debate. Alcalá de Henares: Universidad de Alcalá, 2004. pp. 33-38.

${ }^{21}$ Los resultados de nuestra investigación sobre la documentación de los retratos de Goya conservados en la R.A.H. y las implicaciones de la documentación en el arte, se presentaron en la Facultad de Ciencias de la Documentación de la Universidad Complutense de Madrid en 
La conclusión es que la relación de los museos y la documentación está empezando a cambiar. Como hemos visto, ya existen instituciones culturales que invierten parte de sus recursos en crear fondos bibliográficos y archivísticos variados que apoyen la investigación de la colección artística o arqueológica y que contribuyan a su investigación y conocimiento. Aun así, esta corriente no está generalizada y numerosos museos desconocen las aportaciones positivas que puede suponer tener sus documentos correctamente ordenados, clasificados y localizados para poder explotar todas las posibilidades que ofrecen como fuente de información primaria al servicio de la investigación de la pieza artística o arqueológica.

\section{ANÁLISIS DE LA TIPOLOGÍA DOCUMENTAL}

En este apartado expondremos las principales tipologías documentales localizadas entre la documentación generada por los cuatro retratos de Goya que se conservan en la R.A.H. Para establecer estas categorías hemos tenido en cuenta las tipologías más habituales de documentos administrativos ${ }^{22}$, aunque es necesario señalar que la R.A.H. es una institución semi-privada y como tal genera una documentación que no siempre puede incluirse en dichas tipologías. Además, en nuestro caso existen documentos que bien por la especificidad de su contenido (adquisiciones, préstamos a exposiciones, restauraciones de las obras) o bien por su antigüedad, hemos considerado que requieren una clasificación especial.

\section{a) Expedientes}

El fondo documental del Gabinete de Pintura de la R.A.H. está organizado siguiendo un esquema temporal. Nos referimos aquí solo al Gabinete de Pintura ${ }^{23}$ por ser el conjunto documental que, por sus características de formación y por los documentos que contiene, tiene una mayor importancia para nuestra investigación.

La signatura se forma con el año estimado de creación del documento más un número correlativo escrito detrás de una barra oblicua y otra cifra diferente entre paréntesis. La ordenación se realiza atendiendo al dígito colocado detrás de la

junio de 2010, por lo que en esas fechas desconocíamos por completo que desde el Museo Nacional del Prado se estaba trabajando en esta misma línea de investigación.

22 Manual de documentos administrativos. Madrid: Tecnos: Ministerio de las Administraciones Públicas, 2003. 349 p.

SÁNCHEZ PRIETO, Ana Belén. "Documentos administrativos: un ensayo de diplomática contemporánea". Documentación de las Ciencias de la Información. 1995, nº 18. pp. 193-210.

FERNÁNDEZ BAJON, M ${ }^{\mathrm{a}}$ Teresa. "Documentación administrativa: una revisión de las tipologías documentales administrativas comunes". Revista general de información y documentación. 1996, vol. 6, nº 2, 1996. pp. 67-90.

${ }^{23}$ GONZÁLEZ ZYMLA; FRUTOS SASTRE (2003). 
barra. Es un sistema confuso, que no crea expedientes que reflejen hechos documentales reales, sino que simplemente realiza una ordenación de los escritos de manera temporal.

Así encontramos que el número $/ 1$, abarca desde $G P$ 1780/1(1) hasta $G P$ 1912/1(152). En estos documentos podemos encontrar escritos relativos a encargos y adquisiciones de cuadros, transcripciones de actas, fichas catalográficas, inventarios... Otro ejemplo sería /27, que contiene documentos desde 1917 hasta 1978, incluyendo separatas de artículos del Boletín de la R.A.H., mapas de las habitaciones, inventarios... Sin embargo, esta numeración tampoco es exacta, ya que, por ejemplo, podemos encontrar que los documentos referidos una exposición celebrada en Londres en el año 1963 pueden tener signatura $/ 20 \mathrm{o} / 21$.

Es decir, no existen unos expedientes claros que reflejen un suceso real, sino que dentro de un mismo número encontramos escritos relativos a temas muy diferentes, y en cambio los documentos relativos a una misma actividad pueden estar dispersos en signaturas diferentes.

\section{b) Carpetillas de expediente}

Las carpetillas de expedientes de la R.A.H. siguen dos tipologías similares en las que aparecen una serie de apartados impresos, cuyos datos se rellenan posteriormente con letra cursiva escrita a mano. El modelo más habitual es el que consta de las secciones: REAL ACADEMIA DE LA HISTORIA como encabezamiento, $S E S I O ́ N D E$ que hace referencia a las reuniones de la junta donde la cuestión del expediente ha sido tratada, RESOLUCIÓN Y ASUNTO, referidas a la temática principal de los documentos contenidos en la carpetilla y a las decisiones relacionadas con la tramitación.

Existe otra tipología que se puede encontrar en los documentos realizados entre los años 1900 y 1915. La variación fundamental es el cambio en algunos de los apartados: Número, Legajo, Real Academia de la Historia, SECRETARÍA, SESIÓN del... de... El número posiblemente se refiere al dígito de la carpetilla, dentro de la serie. El legajo generalmente se identifica con la sección a la que la documentación pertenece, en este caso: Retratos Gabinete de Antigüedades o Varios, dependiendo de la fecha del expediente. La mención de la Secretaría probablemente se debía a que es la sección en la que se ejecutaban la mayoría de los documentos. La sesión de Junta continúa teniendo gran importancia en el expediente, ya que es durante estas reuniones cuando se toman las decisiones y se dictan las resoluciones que afectan a los asuntos de la Academia.

Las carpetillas generalmente cumplen la función para la que fueron diseñadas: reunir los documentos relativos a una misma temática, generados en un espacio temporal limitado. En ocasiones se puede encontrar la carpetilla vacía, como testigo de la existencia de un documento que se halla ubicado en otro lugar de la Academia. Un claro ejemplo es el documento GP 1805/1(5): carpetilla de 
expediente de la R.A.H. que debería contener el oficio en el que José de Vargas Ponce comunica a la Academia que su retrató está terminado en casa de Francisco de Goya, por lo que hay que recogerlo y pagarlo. Escrito posteriormente, con letra cursiva, se expresa que este documento se encuentra enmarcado en el salón se sesiones de la Academia.

\section{c) Oficios}

Existen varias comunicaciones remitidas por autoridades administrativas, en las que se explica de manera oficial algún asunto relativo a los cuadros de la R.A.H. Tienen una estructura similar, en la que suele figurar el nombre de la institución o persona remitente, a veces con escudo en el membrete. A continuación aparece el cuerpo de la comunicación en el que se expresan los motivos de la carta. Los oficios terminan con la data crónica y tópica, seguida de la firma, generalmente rubricada, del autor personal de la comunicación. En ocasiones también figura el sello de la institución. En la mayoría de los oficios revisados el destinatario de la misiva aparece en último lugar. Sólo en los documentos generados desde 1996 se sitúa al principio de la comunicación, de forma similar a como se realiza en la actualidad.

Son documentos muy variados remitidos desde diversas instituciones tales como la Dirección General de Bellas Artes, dependiente del Ministerio de Educación Nacional, el Ayuntamiento de Cádiz o la Sociedad Estatal Goya $96^{24}$; o por personas físicas con cargos administrativos: José de Vargas Ponce, en calidad de director de la R.A.H. o el marqués de Pidal ${ }^{25}$ como ministro de Fomento ${ }^{26}$.

\section{d) Minutas}

Existen numerosas minutas de documentos emitidos por la R.A.H. referidos a diversos asuntos, que se han conservado como testigo de las comunicaciones enviadas a instituciones o personas ajenas a la R.A.H. ${ }^{27}$

Generalmente siguen la misma estructura que los oficios descritos en el apartado anterior, aunque es habitual que no aparezca la firma rubricada del autor y que se tienda a usar más abreviaturas que en otros documentos. En algunos de estos papeles aparece escrito al margen la palabra Hecho, indicando que el documento original se realizó y se envió correctamente, aunque no todas están rubricadas.

\footnotetext{
${ }^{24}$ Véanse GP 1963/20(2) y GP 1963/21(3); GP 1855/1(17) y GP 1996/36(4), respectivamente.

${ }^{25}$ Luis Pidal y Mon, marqués de Pidal (Madrid, 1842 - Madrid, 1913), político que ocupó el cargo de ministro de Fomento durante el primer mandato de Francisco Silvela.

${ }^{26}$ Véanse GP 1805/1(5) y GP 1900/2(6).

${ }^{27}$ Véanse GP 1805/1(5) y GP 1900/2(6).
} 
Gracias a la información obtenida de las minutas conservadas con la documentación del Gabinete de Pintura de la R.A.H., que reflejan las comunicaciones y cartas remitidas desde esta corporación, se puede deducir que tal vez existan documentos relacionados con las obras de Goya en los diferentes archivos donde se conservan actualmente los fondos del Ministerio de Educación Nacional, Delegación Provincial de Madrid dependiente del Ministerio de Información y Turismo (1970), Dirección General de Bellas Artes (año 1963), Royal Academy of Arts de Londres, Ayuntamiento de Cádiz, Museo del Prado, Subdirección General de Bienes Muebles (1996), Instituto de Conservación y Restauración de Bienes Culturales ${ }^{28}$, empresa Endesa, Fundación 2 de Mayo y en varios archivos privados como el de Aureliano de Beruete $^{29}$ o José de Vargas Ponce.

\section{e) Cartas}

Las relaciones que establece la R.A.H. con las personas físicas, a menudo se realizan como una comunicación más privada y menos formal.

Existen dos ejemplos muy claros en la documentación consultada: la carta enviada por Aureliano de Beruete a la R.A.H. ${ }^{30}$, como contestación a una misiva anterior en la que la corporación agradecía la restauración del lienzo de Fray Juan Fernández de Rojas. Esta respuesta está fechada en Madrid el 9 de diciembre de 1915 y va dirigida a Juan Pérez de Guzmán y Gallo ${ }^{31}$, como secretario de la R.A.H. La otra carta es un fax enviado por José Manuel Pita Andrade ${ }^{32}$, el día 18 de octubre de 1996 desde Granada,

${ }^{28}$ En adelante el Instituto de Conservación y Restauración de Bienes Culturales aparecerá representado con sus siglas: ICRBC.

${ }^{29}$ Aureliano de Beruete y Moret (Madrid, 1876 - Madrid, 1922), historiador, crítico de arte y Director del Museo del Prado entre 1918 y 1922. MUSEO DEL PRADO [en línea]. Enciclopedia online. <http://www.museodelprado.es/enciclopedia/enciclopedia-on-line/> [Consulta: 2012-03-25].

${ }^{30}$ Véase GP 1915/5(3).

31 Juan Pérez de Guzmán y Gallo (Ronda, Málaga 1841 - Madrid, 1928), abogado, periodista, historiador, militar, que ocupó el cargo de secretario de la R.A.H. desde 1914 hasta su muerte. REAL ACADEMIA DE LA HISTORIA. Base de datos del Centro de Estudios Biográficos [en línea].

$<$ http://www.rah.es:8888/ArchiDocWeb-

$\mathrm{RAH} /$ action/buscarElementos?method=buscar\&tipoBusqueda $=6 \&$ letra $=\mathrm{A}>\quad$ [Consulta: 201203-25]. Todas las biografías que aparezcan sin especificar su fuente, habrán sido obtenidas de esta misma base de datos.

${ }^{32}$ José Manuel Pita Andrade (La Coruña, 1922 - Granada, 2009), historiador, Director del Museo del Prado entre 1978 y 1981, miembro de la Comisión Permanente de dicho Museo y Académico de la R.A.H. desde 1987. MUSEO DEL PRADO [en línea]. Enciclopedia online. <http://www. museodelprado.es/enciclopedia/enciclopedia-on-line/> [Consulta: 2012-03-25]. 
para comunicar a la Academia la posibilidad de restaurar en el taller del Museo del Prado, los retratos de Goya que custodia la institución ${ }^{33}$.

\section{f) Libramientos}

Entre la documentación consultada hay dos libramientos: uno relacionado con el pago de los retratos de Carlos IV y María Luisa de Parma ${ }^{34}$, y otro con el de José de Vargas Ponce ${ }^{35}$. La Academia no posee el documento correspondiente al cuadro de Fray Juan Fernández de Rojas, ya que este lienzo llegó a la institución por donación testamentaria.

En los libramientos los directores de la R.A.H., con todos sus títulos, ordenan al tesorero correspondiente efectuar el pago acordado con Francisco de Goya. El documento está firmado por el censor de la Academia, responsable de garantizar el cumplimiento de las normas de esta corporación, y por el secretario, quien probablemente escribía el documento.

Los dos libramientos consultados tienen una forma y estructura muy similar, con partes escritas a mano y otras impresas. Aparecen encabezadas por el nombre del director de la R.A.H. con letras mayúsculas, seguido de todos sus cargos y títulos. Después se escriben los datos relativos al censor de la Academia, la fecha de ejecución del documento, el artista al que se debe efectuar el abono, el importe del pago y la obra realizada, así como la mención al recibo que debe firmar el interesado y el compromiso de la R.A.H. de ingresar la cantidad acordada en las cuentas del pintor, con la fecha en que se suscribe el documento. Por último se pueden apreciar las firmas del director, censor y secretario, mostrando su acuerdo con el documento.

\section{g) Recibos}

Se puede incluir en esta tipología documental el recibi ${ }^{36}$ con la firma autógrafa de Goya relativo al pago de los retratos de Carlos IV y María Luisa de Parma. Con este documento el pintor afirma haber percibido la cantidad acordada en concepto de abono por la ejecución de los cuadros de los Reyes.

También existe otra tipología documental a la que se le denomina recibo. Está relacionada con el depósito y posterior retirada de un aparato de medición de datos medioambientales en la R.A.H. por parte del ICRBC ${ }^{37}$. Estas acciones se realizan

\footnotetext{
${ }^{33}$ Véase GP 1996/36(2).

${ }^{34}$ Véase GP 1789/1(3).

${ }^{35}$ Véase GP 1806/1(7).

${ }^{36}$ Véase GP 1789/1(3).

${ }^{37}$ Véanse GP 1996/36(5) y GP 1996/36(6).
} 
en el año 1996, enmarcadas dentro de un estudio sobre el estado y posible restauración de los retratos realizados por Goya.

\section{h) Informes}

Existen varios informes técnicos relacionados con temáticas muy diferentes y por tanto con estructuras poco definidas. La finalidad de estos documentos es reunir datos sobre un asunto concreto en un tiempo determinado. Así, por ejemplo, existe un informe del año 1858 en el que se enumeran las monedas adquiridas por la R.A.H. desde 1856 hasta 1858, incluyendo la donación del retrato de Fray Juan Fernández de Rojas ${ }^{38}$.

Otro claro ejemplo es el informe técnico sobre el estado de los retratos pintados por Goya, realizado en 1996 por el ICRBC, para estudiar una posible restauración de los lienzos y preparar un plan para una mejor conservación de los mismos ${ }^{39}$.

\section{i) Notas internas}

Son comunicaciones referidas a múltiples temas entre distintos académicos de la R.A.H. Tienen un formato variable difícil de tipificar. En ocasiones se generan como transcripciones de un documento anterior o para notificar la recepción de un oficio con información importante para la Academia, remitido desde cualquier entidad ajena a la corporación ${ }^{40}$. También pueden ser breves documentos escritos por algún académico que acompañan y explican otros informes u oficios que se reciben en la R.A.H. desde el exterior ${ }^{41}$.

Quizás no se conservan demasiados documentos de este tipo porque son meros papeles de trámite que, por lo general, no son considerados material de archivo, ya que contienen informaciones reiterativas presentes en otros escritos.

\section{j) Actas de sesiones de la Junta}

Las actas de las sesiones de la Junta de la R.A.H. son la documentación más numerosa y que más información aporta sobre la vida de los cuadros dentro de la Academia. En estas sesiones se discuten todos los asuntos y se toman las decisiones correspondientes, que quedan reflejadas en los libros de actas para la posterioridad. También se contemplan sucesos externos que puedan guardar relación con la vida de la corporación. Se conservan en el despacho del secretario

\footnotetext{
${ }^{38}$ Véase GN 1856-1858/1(2).

${ }^{39}$ Véase GP 1996/36(7).

${ }^{40}$ Véanse documentos GP 1857/1(26), GP 1857/1(27) y GP 1693/21(2).

${ }^{41}$ Véase, GP 1996/36(8).
} 
de esta institución y han sido estudiadas y publicadas por Jorge $\mathrm{Maier}^{42} \mathrm{y}$ por Herbert González y Leticia Frutos ${ }^{43}$.

Existen desde $1738^{44}$ y en nuestro recorrido a través de la documentación generada por las obras de Goya, el primer testimonio lo encontramos el 2 de enero de $1789^{45}$ cuando se menciona por primera vez el posible encargo de unos retratos de los Reyes Carlos IV y María Luisa de Parma para que presidan el Salón de Juntas de la Academia.

La estructura de las actas de sesiones apenas ha evolucionado desde el siglo XVIII: comienza con la fecha de la reunión de la Junta. A continuación se menciona al director y generalmente al censor y al secretario. En el margen del libro se anotan todos los académicos de número y correspondientes que han asistido a la sesión. En el primer párrafo normalmente también se indica que el acta de la sesión anterior ha sido aprobada. En el cuerpo del acta aparecen todos los asuntos que han surgido durante la semana y que deben tratarse en la Junta. Las sesiones terminan cuando se han tratado todos los temas pendientes de discusión y ha transcurrido el tiempo establecido en los estatutos de la R.A.H.

Las actas de sesiones nos han permitido conocer la existencia de documentos que no han sido localizados durante este estudio e incluso datar con exactitud algunos escritos, cuya fecha estimada estaba equivocada ${ }^{46}$.

\section{k) Inventarios}

Se han localizado varios inventarios de las piezas que se conservan en la R.A.H. Quizás alguna de estas recopilaciones está relacionada con el cambio de director o anticuario en la Academia, ya que era costumbre que en esas ocasiones se realizase una relación de todas las piezas depositadas en la institución.

Así encontramos que el primer inventario está fechado aproximadamente en $1912^{47}$. Efectivamente en este año falleció Marcelino Menéndez y Pelayo ${ }^{48}$ y fue sustituido en el cargo de director por Fidel Fita y Colomer ${ }^{49}$.

${ }^{42}$ MAIER ALLENDE, Jorge. Noticias de Antigüedades de las Actas de Sesiones de la R.A.H. (1738-1791). Madrid: Real Academia de la Historia, 2011. 484 p.; Noticias de Antigüedades de las Actas de Sesiones de la R.A.H. (1792-1833). Madrid: Real Academia de la Historia, 2003. 256 p. y Noticias de Antigüedades de las Actas de Sesiones de la R.A.H. (18341874). Madrid: Real Academia de la Historia, 2008. 406 p.

43 GONZÁLEZ ZYMLA; FRUTOS SASTRE (2002 y 2003).

${ }^{44}$ ALMAGRO-GORBEA, Martín. "Prólogo". En: MAIER, Jorge. Noticias de antigüedades de las Actas de sesiones de la Real Academia de la Historia (1792-1833). Madrid: Real Academia de la Historia, 2003. 256 p.

${ }^{45}$ Véase acta 1789/01/02.

${ }^{46}$ Véanse GP 1912/1(72) y acta 1915/12/17.

${ }^{47}$ Véase GP 1912/1(80). 
También en el año $1913^{50}$ se realiza un listado de las monedas y medallas de oro que entrega el anticuario saliente, Fidel Fita, al entrante, José Ramón Mélida ${ }^{51}$. Igualmente en 1909 se genera otro inventario coincidiendo con el cambio de anticuario entre Juan Catalina García ${ }^{52}$ y Fita ${ }^{53}$.

Otro inventario se realiza tras recibir un oficio remitido desde la Delegación Provincial del Ministerio de Información y Turismo solicitando una enumeración de las piezas disponibles en la R.A.H. para que sean incluidas en la publicación Museos de España ${ }^{54}$.

Existe un tercer conjunto documental realizado en torno a 1978 que se corresponde con un fichero en el que se cataloga la colección de cuadros de la R.A.H. ${ }^{55}$ Cada tarjeta especifica el autor, las medidas y la procedencia de cada cuadro y está acompañada de una fotografía, en blanco y negro. Estas fichas son los primeros documentos gráficos que se conservan en la R.A.H. generados por los cuadros de Goya.

Además varias de las separatas del Boletín de la Real Academia de la Historia $^{56}$ que se conservan con la documentación del Gabinete de Pintura están relacionadas con inventarios o realizadas como si fueran una recopilación de información sobre los distintos cuadros que se conservan en la Academia.

48 Marcelino Menéndez y Pelayo (Santander, 1856 - Santander, 1912), Director de la R.A.H. desde el 17 de diciembre de 1909 hasta su muerte.

49 Fidel Fita i Colomé (Arenys de Mar, Barcelona, 1835 - Madrid, 1918). Jesuíta, historiador, arqueólogo, numismático, hebraísta, paleógrafo, epigrafista, catedrático. Fue Anticuario de la R.A.H. desde enero de 1909 hasta diciembre de 1913, cuando fue elegido Director de la Corporación, cargo que ya había ocupado de forma provisional desde mayo de 1912 y en el que se mantendría hasta su muerte.

${ }^{50}$ Véase GP 1913/4.

${ }^{51}$ José Ramón Mélida y Alinari (Madrid, 1856 - Madrid, 1933), arqueólogo, museógrafo, catedrático, anticuario, académico de la R.A.H. desde el 16 de febrero de 1906 y Anticuario de la misma desde 1913 hasta su muerte.

52 Juan Catalina García López (Salmeroncillos de Abajo, Cuenca, 1845 - Madrid, 1911) Anticuario, historiador, catedrático, político, bibliófilo, bibliógrafo, arqueólogo, académico de la R.A.H. desde el 18 de abril de 1890, Anticuario de la misma desde el 13 de diciembre de 1901, hasta el 11 de diciembre de 1908, momento en que fue elegido secretario perpetuo de la Corporación.

${ }^{53}$ MARTÍN ESCUDERO, Fátima; CANTO GARCÍA, Alberto; CEPAS, Adela. Archivo del Gabinete Numario: Catálogo e índices. Madrid: Real Academia de la Historia, 2004. 464 p. Véanse GN 1913/1(1-2), pp. 325-326 y GN 1909/2(1-3), pp. 324.

${ }^{54}$ Véase GA 1970/1(2).

${ }^{55}$ Véase GP 1978/25(2).

${ }^{56}$ Las separatas del Boletín de la Real Academia de la Historia serán tratadas en un apartado específico posterior. 


\section{l) Seguros}

Cada vez que una pieza abandona la R.A.H. debería contratarse un seguro que proteja el traslado de la obra y garantice su devolución en perfecto estado. Lo cierto es que apenas se conserva documentación de este tipo.

La primera mención a un documento de esta clase, la localizamos en una carta remitida por el marqués de Pidal en su función de ministro de Fomento, al director de la R.A.H. para solicitar el préstamo de los cuadros realizados por Goya que posee la institución, con el fin de que formen parte de una exposición conmemorativa de Velázquez que se deseaba organizar en el año $1899^{57}$. El marqués de Pidal expresa que si la Academia acepta prestar sus lienzos, se generará un resguardo que garantice su traslado al Museo Nacional (hoy Museo del Prado), sin sufrir daños. Este resguardo viene a ser un seguro actual por el que el ministro se responsabiliza directamente de la correcta conservación de los cuadros mientras se encuentran fuera de la R.A.H. Esta muestra no llegó a realizarse por lo que no se conserva ningún documento de este tipo.

En 1963 la Royal Academy of Arts de Londres organiza una exposición de Goya en la ciudad británica. En los documentos que se generan en torno al préstamo del retrato de Fray Juan Fernández de Rojas, sí se menciona la contratación de un seguro del cuadro por valor de cinco millones de pesetas ${ }^{58}$. El documento original no ha sido localizado, pero gracias a las actas de sesiones, a los oficios remitidos desde la Dirección General de Bellas Artes y a las minutas conservadas, sabemos que existió.

En 1996, con motivo de una posible restauración de los cuadros de Goya, también se hace referencia a que si la Academia accede a que se realice la intervención, se contratará un seguro que garantice el traslado hasta el ICRBC ${ }^{59}$.

\section{m) Artículos y separatas de publicaciones periódicas}

Entre la documentación del Gabinete de Pintura se han conservado varias copias de separatas del Boletín de la Real Academia de la Historia por su relación directa y su interés para el estudio de los cuadros que se custodian en la corporación.

En 1917 Juan Pérez de Guzmán y Gallo escribe un artículo publicado en el Boletín de la R.A.H., tomo LXX, sobre los retratos y bustos que forman la colección artística de la R.A.H. ${ }^{60}$. Lo mismo ocurre en 1946 con el artículo Los cuadros de Goya en la Real Academia de la Historia firmado por Francisco Javier

\footnotetext{
${ }^{57}$ Véase GP 1899/2(2).

${ }^{58}$ Véanse GP 1693/21(1) y GP 1963/21(2).

${ }^{59}$ Véase GP 1996/36(4).

${ }^{60}$ Véase GP 1917/27(3).
} 
Sánchez Cantón ${ }^{61}$ en el que de nuevo se realiza un estudio sobre los retratos de Mariano Luis de Urquijo ${ }^{62}$, Carlos IV, María Luisa de Parma, Fray Juan Fernández de Rojas y José de Vargas Ponce ${ }^{63}$.

\section{n) Documentación gráfica y fotográfica}

Hemos localizado unas reproducciones en blanco y negro relacionadas con el fichero de los cuadros de la R.A.H. ${ }^{64}$. Obviamente, no existe ningún testimonio gráfico del proceso de ejecución de estos retratos, aunque sí existen bastantes reproducciones contemporáneas de los cuadros utilizadas por ejemplo en el mundo editorial.

Dentro de la documentación gráfica también podría incluirse la realización de unos planos de las estancias del Palacio del Nuevo Rezado, sede de la R.A.H., donde se encuentran los cuadros y otros objetos de la colección de Antigüedades que posee la institución. Están dibujados a mano, parece que por María Luisa Ruiz Trapero, en torno al año $1978^{65}$.

Lo cierto es que tenemos constancia de que la documentación fotográfica e incluso audiovisual es actualmente un elemento fundamental en los procesos creativos de artistas contemporáneos, convirtiéndose así en una nueva tipología que desde el mundo de la documentación no podemos olvidar.

\section{o) Correos electrónicos}

Los e-mails serían más un soporte de información que un tipo documental, pero por ser una forma novedosa, que hace evolucionar la clásica comunicación a través de cartas, oficios, instancias... consideramos adecuado mencionarlos en un apartado distinto.

El intercambio de información y las negociaciones dejan de ser en formato papel para realizarse a través de Internet, en un entorno virtual que agiliza los procesos comunicativos. Esta nueva modalidad crea un problema que antes no existía para la documentación y la archivística: estos mensajes generalmente

${ }^{61}$ Francisco Javier Sánchez Cantón (Pontevedra, 1891 - Pontevedra, 1971), historiador, catedrático, ensayista y crítico de arte, fue académico de la R.A.H. desde 1934 y Director de la misma desde diciembre de 1956 hasta su muerte.

${ }^{62}$ Mariano Luis de Urquijo y Muga (Bilbao, 1768 - París, 1817), político, diplomático, abogado y estadista. Jesús Valverde Madrid ya señaló en "El cuadro de San Eulogio, de Agustín Grande, en el Seminario de Córdoba". Boletín de la Real Academia de Córdoba. 1964, pp. 368-404, que este lienzo no era en realidad obra de Goya, sino de Francisco Agustín y Grande. En la actualidad esta es la teoría vigente y así aparece clasificado en el Catálogo de Pinturas de la R.A.H. GONZÁLEZ ZYMLA; FRUTOS SASTRE (2003) pp. 26-30.

${ }^{63}$ Véase GP 1946/27(6).

${ }^{64}$ Véase GP 1978/25(2).

${ }^{65}$ Véase GP 1978/27(4). 
quedan en el ámbito privado del correo personal, en pocas instituciones pasan a ser parte de expedientes y, a largo plazo, la información que contienen probablemente se perderá. También en este ámbito nos encontramos con una de los granes problemas que se plantean a los profesionales de nuestra área en la actualidad: la perdurabilidad de los soportes y la conservación de su información.

Es cierto que en muchos casos los datos incluidos en estos correos son meros documentos de trámite, que si se generasen en formato papel tampoco se considerarían material de archivo, pero en ocasiones pueden contener información de gran importancia. De hecho hemos podido localizar varios correos electrónicos impresos, formando parte de expedientes de la R.A.H.

\section{VACÍOS DOCUMENTALES}

El estudio del corpus nos ha permitido detectar la ausencia de documentos que debieron existir, pero que por motivos desconocidos no se conservan actualmente en los fondos de la R.A.H. Un claro ejemplo sería un oficio enviado por Pascual Gutiérrez como albacea de Santiago Manuel de Arteaga ${ }^{66}$, que debería estar fechado en torno al año 1857 , y por el que se comunicaba que, por donación testamentaria, el retrato de Fray Juan Fernández de Rojas pasaba a formar parte de la colección de la R.A.H. ${ }^{67}$

En el acta de la sesión del viernes 4 de abril de $1964^{68}$, se menciona una carta remitida por el director de la Royal Academy of Arts de Londres, en la que se agradece a la R.A.H. el préstamo del retrato de Fray Juan Fernández de Rojas, dicha carta no ha sido localizada entre la documentación consultada.

También hemos detectado la ausencia de informes técnicos y recibos que justifiquen la salida y posterior devolución de los retratos de la R.A.H., en las ocasiones en las que los cuadros han participado en exposiciones o bien han sido sometidos a restauraciones fuera de la Academia.

\section{FASES DE LA VIDA DE UNA OBRA DE ARTE}

El análisis del corpus nos permite establecer una serie de fases en la vida de una obra de arte que invariablemente generan documentación.

\section{a) Encargo}

\footnotetext{
${ }^{66}$ No hemos localizado ninguna biografía sobre Santiago Manuel de Arteaga.

${ }^{67}$ Oficio mencionado en los documentos: actas 1857/02/27, GP 1857/1(27) y GA 1857/1.

${ }^{68}$ Véase acta 1964/04/04.
} 
La composición de los retratos tanto de Carlos IV y María Luisa de Parma, como de José de Vargas Ponce se contempla en las actas de las sesiones de la Junta de enero y marzo de $1789^{69}$ y mayo de $1805^{70}$ respectivamente. No se ha localizado ningún papel donde se refleje las negociaciones del precio y de las condiciones de ejecución de los cuadros, por lo que tal vez estos acuerdos se realizaron de forma oral.

\section{b) Creación de la obra artística}

Como hemos señalado anteriormente, tenemos constancia de que muchos artistas contemporáneos documentan gráficamente el proceso creativo de sus obras, generando series documentales de gran valor informativo.

Sobre los retratos realizados por Goya no se conserva ningún tipo de documento relacionado con esta fase. Obviamente era imposible realizar una plasmación gráfica del proceso, pero sí podrían haber existido bocetos sobre los cuadros o incluso alguna mención a estos trabajos en las cartas personales del pintor zaragozano.

\section{c) Adquisición}

La recepción de los cuadros queda reflejada siempre en las actas de sesiones de la R.A.H. Los cuadros de los Reyes se colocan en la Academia en la semana del 11 de septiembre de $1789^{71}$. El retrato de José de Vargas Ponce es reclamado por el propio director de la R.A.H. desde Pamplona el 31 de diciembre de $1805^{72}$, se recoge en casa de Goya y se deposita en la Academia entre el 10 y el 23 de enero de $1806^{73}$. En el acta del 27 de febrero de $1857^{74}$ se menciona haber recibido el lienzo de Fray Juan Fernández de Rojas por donación testamentaria de Santiago Manuel de Arteaga.

\section{d) Pago de la obra}

En la R.A.H. se conservan los libramientos redactados para efectuar el abono de los retratos de los Reyes y de Vargas Ponce a Goya ${ }^{75}$. En el caso de la Pareja

\footnotetext{
${ }^{69}$ Véanse actas $1789 / 01 / 02$ y 1789/03/20.

${ }^{70}$ Véase acta 1805/05/10.

${ }^{71}$ Véase acta 1789/09/11.

${ }^{72}$ Véase GP 1805/1(5).

${ }^{73}$ Véanse acta 1806/01/10 y documento GP 1806/1(7).

${ }^{74}$ Véase acta 1857/02/27.

${ }^{75}$ Véanse GP 1789/1(3) y GP 1806/1(7).
} 
Real también se conserva el recibí con la firma autógrafa del pintor zaragozano ${ }^{76}$. Los pagos de las obras quedan también reflejados en los libros de actas de sesiones de la Junta de la Academia.

No existe documentación de este tipo sobre el retrato de Fernández de Rojas, ya que como se ha mencionado anteriormente, ingresa en la Academia por donación testamentaria.

\section{e) Restauración}

Todos los lienzos de Goya han sido sometidos a restauraciones para preservar la delicadeza y el valor de las pinturas. Tenemos constancia de que en 1915 Aureliano de Beruete realizó una intervención en el cuadro de Fray Juan Fernández de Rojas ${ }^{77}$ y que en 1963 se reparó una hendidura que existía en el lienzo ${ }^{78}$.

En 1977 los retratos de Carlos IV y María Luisa de Parma fueron sometidos a una limpieza en el Museo del Prado ${ }^{79}$. En 1996, coincidiendo con el doscientos cincuenta aniversario del nacimiento de Goya, se desarrolla un proyecto de restauración de los lienzos de la Academia ${ }^{80}$, que parece ser no llegó a ejecutarse. En la mayoría de estas intervenciones se ha detectado que posiblemente faltan documentos que se debieron generar en el momento, pero que no han sido localizados en este estudio.

Es probable que los retratos pintados por Goya hayan sido restaurados en más ocasiones, pero la documentación relativa a estas acciones no ha sido localizada.

\section{f) Exposición}

Los retratos de Goya han sido expuestos en numerosas muestras nacionales e incluso internacionales. Como ejemplos, destacaremos: el proyecto de exposición para conmemorar el aniversario de Velázquez $(1899)^{81}$; la muestra celebrada con motivo del traslado de los restos de Francisco de Goya al mausoleo del Cementerio de San Isidro de Madrid (1900) ${ }^{82}$; la exhibición Goya y su tiempo organizada por la Royal Academy of Arts de Londres $(1963)^{83}$; La Nación Soberana: Proclamas y bandos de 1808, celebrada en Madrid en el año 2008 o Royal Splendor in the Enlightenment: The collection of

${ }^{76}$ Véase GP 1789/1(3).

${ }^{77}$ Véanse actas $1915 / 10 / 22$ y 1915/12/10, y documentos del expediente GP 1915/5.

${ }^{78}$ Véase acta 1964/03/20.

${ }^{79}$ Véanse actas de 1977/01/07 a 1977/05/13.

${ }^{80}$ Véase GP 1996/36.

${ }^{81}$ Véanse GP 1899/2 y acta $1899 / 05 / 05$.

${ }^{82}$ Véanse GP 1900/2 y acta 1900/04/06.

83 Véanse GP 1963/21, acta 1963/10/04, acta 1963/10/18, acta 1963/11/13, acta 1963/11/29, acta 1963/12/13, acta 1964/03/04 y acta 1964/03/20. 
Charles IV of Spain organizada por el Museo Meadous de Dallas (Estados Unidos) entre marzo y julio de $2010^{84}$.

\section{g) Otros}

Como se ha mencionado anteriormente, los cuadros de Goya han sido inventariados varias veces en la R.A.H., junto a las otras piezas del Gabinete de Antigüedades ${ }^{85}$.

Además se tiene constancia de que en 1855 el alcalde de Cádiz solicitó enviar a un pintor comisionado para que realizase una copia del retrato de José de Vargas Ponce, quien había nacido en dicha ciudad ${ }^{86}$.

El Gabinete de Pintura ha recogido algunas de las separatas del Boletín de la R.A.H. referidas a sus objetos artísticos, quizás porque debido a su aporte informativo, ha considerado interesante que se conserven fotocopiados con el resto de la documentación sobre las pinturas ${ }^{87}$.

Los retratos realizados por Goya seguramente han sido objeto de otros muchos estudios científicos, que sería interesante reunir para realizar una reconstrucción completa de la vida de los cuadros.

\section{RECONSTRUCCIÓN HISTORIOGRÁFICA}

Una de las mayores aportaciones del análisis de la documentación generada por la obra artística es poder realizar una reconstrucción historiográfica de la vida de la obra. A continuación mostraremos los datos más importantes de la historia de cada retrato:

\section{a) Carlos IV y María Luisa de Parma}

La primera mención a los retratos aparece en la sesión del 2 de enero de $1789^{88}$, cuando se decide realizar unos retratos de los Reyes para la R.A.H. con motivo de la coronación de los Monarcas. El 20 de marzo se retoma este tema y se encomienda a Jovellanos que realice el encargo de los cuadros ${ }^{89}$. El artista elegido es Francisco de Goya, quien además era el Pintor de Cámara de los Reyes.

Por las fechas de las actas se puede estimar que los cuadros llegaron a la R.A.H. entre el 5 y el 10 de septiembre, ya que el día 11 se encarga realizar el

${ }^{84}$ La documentación relativa a las exposiciones contemporáneas se puede localizar en la Secretaría del Anticuario.

${ }^{85}$ Véanse GP 1912/1(80), GP 1978/25(2) y GA 1970/1(2).

${ }^{86}$ Véanse GP 1855/1(17) y GP 1855/1(18).

${ }^{87}$ Véanse GP 1913/4, GP 1913/27(7), GP 1917/27(3) y GP 1946/27(6).

${ }^{88}$ Véase acta 1789/01/02.

${ }^{89}$ Véase acta 1789/03/20. 
pago al pintor ${ }^{90}$, dando lugar al recibí con la firma autógrafa de Goya ${ }^{91}$. Realmente el tesorero de la R.A.H. no saca el dinero del arca hasta la semana del 12 de octubre $^{92}$. La cantidad pagada fueron 6.000 reales de vellón, una cifra superior a la abonada por retratos similares ${ }^{93}$, lo que quizás indica que estos cuadros fueron realizados con una menor intervención del taller del pintor.

Parece que para en el correcto desarrollo de la serie documental falta un primer documento: el contrato por el que la R.A.H. encargó la realización a Goya de los lienzos de la pareja real, y en el que quizás deberían especificarse las condiciones de ejecución de estos cuadros, como sí ocurrió en $1808^{94}$, cuando se encargó a Antonio Carnicero ${ }^{95}$ que pintase un retrato de Fernando VII.

Los días 22 y 23 de septiembre ${ }^{96}$ los Reyes visitaron la Academia y mostraron su conformidad con los retratos realizados por Goya. No sabemos nada más de los mismos hasta 1899, cuando en el mes de mayo el marqués de Pidal, como ministro de Fomento, solicita el préstamo de los retratos ${ }^{97}$. El motivo era la celebración de una exposición conmemorativa del tercer centenario del nacimiento de Velázquez, que finalmente no se realizó ${ }^{98}$. Apenas un año después, en marzo de $1900^{99}$, el marqués de Pidal vuelve a solicitar los cuadros para una exposición, está vez dedicada a Goya, organizada con motivo del traslado de los restos del pintor al mausoleo del Cementerio de San Isidro de Madrid.

El catálogo del Gabinete de Pintura ${ }^{100}$ fecha sobre el año 1912 unas transcripciones de los libros de actas de $1789^{101}$ realizadas por Juan Pérez de Guzmán y Gallo, en las que reunía los párrafos relacionados con los retratos de los Reyes. Sobre la motivación de estas copias formulamos varias hipótesis, pero finalmente descubrimos leyendo los libros de actas, que las transcripciones se

${ }^{90}$ Véase acta 1789/09/11.

${ }^{91}$ Véase GP 1789/1.

${ }^{92}$ Véase acta 1789/10/16.

${ }^{93}$ Tenemos constancia de que en 1787, fecha en la que Goya aun no tenía el cargo de pintor de Cámara, el Banco de San Carlos le paga 10.000 reales de vellón por la ejecución de tres retratos que representaban al Rey Carlos III, al conde de Altamira y al marqués de Tolosa. Igualmente se ha recogido que otros retratos de características similares de Carlos IV y María Luisa de Parma, fueron pagados por un precio aproximado de 2.000 reales de vellón. GONZÁLEZ ZYMLA; FRUTOS SASTRE (2003) pp. 106-113.

${ }^{94}$ Véase acta $1808 / 09 / 02$.

95 Antonio Nicanor Carnicero Mancio (Salamanca, 1748 - Madrid, 1814), grabador y pintor de Cámara de Fernando VII.

${ }^{96}$ Véase acta $1789 / 09 / 25$.

${ }^{97}$ Véase GP 1899/2(2). En la sesión del mismo día, acta 1899/05/05, Cesáreo Fernández Duro como secretario de la Corporación, hace constar la recepción de este oficio.

${ }^{98}$ Véanse GP 1899/2(4) y acta 1900/04/06.

${ }^{99}$ Véase GP 1900/2(5).

${ }^{100}$ GONZÁLEZ ZYMLA; FRUTOS SASTRE (2003).

${ }^{101}$ Véase GP 1912/1(72). 
realizaron en el año $1915^{102}$. En esta misma sesión aparece por primera vez la idea de enmarcar y exponer públicamente los documentos más interesantes, entre los que se encuentra el recibí con la firma autógrafa de Goya ${ }^{103}$.

Formando parte de la documentación del Gabinete de Pintura se hallan las fotocopias de varios artículos de la R.A.H. relacionados con los cuadros de Goya. Es curioso que en un artículo escrito por Juan Pérez de Guzmán y Gallo en 1917, se recogen unas palabras de Aureliano de Beruete en las que dice:

En nada merma esto su originalidad. La de los dos de la Real Academia de la Historia se halla comprobada y documentada, y por cierto es bien curiosa, y las fechas que nos da a conocer y la intervención de Jovellanos en el encargo de los cuadros, comprueban la data de las pinturas y la buena amistad y protección que ya desde estos años unía al insigne asturiano y al pintor de Fuendetodos ${ }^{104}$.

Es decir, ya en una fecha tan temprana, Beruete realiza una valoración positiva de la documentación conservada y defiende su utilidad para la investigación, pocos estudios se han elaborado desde entonces en esta dirección.

En 1977 los retratos de Carlos IV y María Luisa de Parma son sometidos a una limpieza en el Taller de Restauración del Museo del Prado ${ }^{105}$. Después de esta intervención se solicita que los cuadros puedan ser visitados como parte de la colección museística de la R.A.H ${ }^{106}$.

La documentación muestra que los cuatro retratos de Goya fueron inventariados en los años $1903^{107}, 1912^{108}, 1913^{109}, 1970^{110}$ y $1978^{111}$.

En 1996 se celebró el 250 aniversario del nacimiento de Francisco de Goya. Por este motivo, desde el Ministerio de Cultura, se promovió una campaña de estudio y restauración de obras del pintor zaragozano ${ }^{112}$.

${ }^{102}$ Véase acta 1915/12/17.

${ }^{103}$ Véase GP 1789/1(3)2.

${ }^{104}$ PÉREZ DE GUZMÁN Y GALLO, Juan. "Retratos y bustos de la Real Academia de la Historia". Boletín de la Real Academia de la Historia. 1917, tomo LXX. p. 190. La obra original donde aparecía este texto es: BERUETE Y MORET, Aureliano de. Goya Composiciones y figuras. (Madrid, 1917. Impreso por Blass y Cia.) $176 \mathrm{p}$.

BERUETE Y MORET, Aureliano de. "Adiciones". Boletín de la Real Academia de la Historia”. Madrid, 1917.

${ }^{105}$ Véanse acta 1977/02/04, acta 1977/02/11 y acta 1977/05/13.

${ }^{106}$ Véase acta 1977/05/13.

${ }^{107}$ Véase GP 1978/25(2).

${ }^{108}$ Véase GP 1912/3(18).

${ }^{109}$ Véase GP 1913/4.

${ }^{110}$ Véase GA 1970/1(2).

${ }^{111}$ Véase GP 1978/25(2). 
Tenemos constancia de que en los últimos años los retratos de Carlos IV y María Luisa de Parma han formado parte de estas exposiciones: Campomanes y su tiempo, celebrada en Madrid en 2003; La Nación Soberana: Proclamas y bandos de 1808, Madrid, 2008; Gusto Neoclásico. Arte y poder en la Corte de España, Madrid, 2009; Royal Splendor in the Enlightenment: The collection of Charles IV of Spain, Museo Meadous de Dallas, marzo-julio, 2010 ${ }^{113}$.

\section{b) Fray Juan Fernández de Rojas}

Conviene señalar que por la falta de documentación, actualmente no se ha podido determinar la fecha de ejecución de esta obra, aunque la mayoría de los expertos lo sitúan entre 1795 y 1805.

En 1857 la R.A.H. recibió el retrato de Fray Juan Fernández de Rojas por donación testamentaria de Santiago Manuel de Arteaga, sobrino de Rojas, para que se conservase con los de los otros continuadores de la España Sagrada ${ }^{114}$, aunque sus avances en la redacción de la gran obra histórico - religiosa fueron insignificantes.

Este cuadro pudo generar una serie documental que en la actualidad no se conserva en la R.A.H., aunque los estudios artísticos consultados sostienen que lo más probable es que Goya realizase el retrato del fraile por simpatía, por lo que si no hubo un encargo previo, no tendría por que existir ningún documento relacionado.

Consultando nuestro corpus hemos localizado varios documentos contradictorios sobre quién fue el albacea de Arteaga: Pascual de Gayangos ${ }^{115} \mathrm{o}$ Pascual Gutiérrez ${ }^{116}$. Gayangos aparece como albacea en una nota interna que recoge los trabajos realizados por él durante ese año ${ }^{117}$. Mientras que Pascual Gutiérrez se menciona en algunos casos como albacea, incluso existe una minuta de oficio redactada para agradecerle la donación ${ }^{118}$.

La duda surge porque la nota interna se redacta únicamente para señalar los trabajos de don Pascual de Gayangos en dicho año. Se puede deducir que posiblemente fuera redactada por él mismo o por una persona cercana al interesado. Pudo ser una casualidad del momento confundir los apellidos Gutiérrez con Gayangos, ya que el nombre es el mismo, pero resulta extraño que este error no fuera corregido por los académicos o por el propio interesado.

\footnotetext{
${ }^{112}$ Véanse GP 1996/36(1), GP 1996/36(2), GP 1996/36(5), GP 1996/36(6), GP 1996/36(7), GP 1996/36(8), GP 1996/36(9), acta 1996/06/28 y acta 1996/10/11.

113 Como ya hemos mencionado, la documentación relativa a las exposiciones e intervenciones recientes se encuentra en la Secretaría del Anticuario.

${ }^{114}$ Véase acta $1857 / 02 / 27$

115 Pascual de Gayangos y Arce (Sevilla, 1809 - Londres, 1897), archivero, intérprete, bibliófilo, senador, académico de la R.A.H. desde el 5 de marzo de 1847 hasta su muerte.

${ }^{116}$ No se ha localizado ningún dato de quién pudo ser Pascual Gutiérrez.

${ }^{117}$ Véase GP 1857/1(26).

${ }^{118}$ Véase GP 1857/1(27).
} 
Por otro lado, sobre las mismas fechas Antonio Delgado ${ }^{119}$ realizó un informe de donaciones de monedas a la R.A.H. recibidas entre los años 1856 y $1857^{120}$, en el que se menciona la recepción del retrato del fraile agustino para que se conserve con los de los otros continuadores de la España Sagrada. En este documento aparece el nombre de Pascual Gutiérrez, aunque en vez de manifestarse como albacea de Santiago Manuel de Arteaga, se menciona como sobrino donante de Fray Juan Fernández de Rojas. Antonio Delgado había trabajado en numerosas ocasiones con Pascual de Gayangos, por lo que es difícil que se equivocase al escribir el apellido de su amigo.

Conviene señalar que en los estudios oficiales sobre este retrato, aparece Pascual Gutiérrez como albacea ${ }^{121}$.

En 1915 Antonio de Beruete realizó una restauración del lienzo, que después generó un informe técnico favorable de José Ramón Mélida ${ }^{122}$.

En 1963, desde la Dirección General de Bellas Artes se solicitó el préstamo de los retratos de Carlos IV, María Luisa de Parma y Fray Juan Fernández de Rojas, para la exposición monográfica Goya and his time organizada por la Royal Academy of Arts de Londres ${ }^{123}$. Los académicos decidieron enviar solo el del fraile agustino por considerar que tenía un mayor interés artístico ${ }^{124}$. Sabemos que el seguro del cuadro se fijó en cinco millones de pesetas ${ }^{125}$ y que la exposición supuso un gran éxito que el presidente de la Royal Academy of Arts manifestó en una carta dirigida a la R.A.H. ${ }^{126}$

Cuando el retrato llegó a Madrid, se restauró en los talleres del Museo del Prado de una incisión en el lienzo que ya tenía anteriormente ${ }^{127}$.

En 2008 participó en la exposición Goya en tiempos de Guerra del Museo Nacional del Prado. Debido a su delicado estado de conservación, no es un cuadro que salga con frecuencia de la R.A.H.

119 Antonio Delgado Hernández (Sevilla, 1805 - Huelva, 1879) Historiador, arqueólogo, profesor, alcalde, catedrático, diputado, epigrafista, diplomático, numismático, académico de la R.A.H. desde el 5 de marzo de 1847, Anticuario de la Corporación desde el 14 de julio de 1848 hasta diciembre de 1867.

${ }^{120}$ Véase GA $1857 / 1$.

${ }^{121}$ GONZÁLEZ ZYMLA; FRUTOS SASTRE (2003), p. 116.

${ }^{122}$ No se ha localizado ningún documento relacionado con la restauración, pero gracias a las cartas GP 1915/5(2) y GP 1915/5(3) podemos saber que el informe final existió.

${ }^{123}$ Véase acta $1963 / 10 / 04$.

${ }^{124}$ Véase GP 1963/20(3), que se corresponde con la minuta enviada a la Dirección General de Bellas Artes, firmada por Julio Guillén, como secretario de la R.A.H.

${ }^{125}$ Véase acta 1963/10/18.

${ }^{126}$ Véase acta 1964/04/04. La carta original no se ha localizado, pero tenemos noticia de que existió por los libros de actas.

${ }^{127}$ Véase acta 1964/03/20. 


\section{c) José de Vargas Ponce}

José de Vargas Ponce fue elegido director de la R.A.H. el 30 de noviembre de $1804^{128}$. Era costumbre realizar un retrato de todos los hombres que ocupaban este cargo e incorporarlos a la colección de la Academia, por lo que en mayo de $1805^{129}$ se tomó la decisión de encargarlo. El propio Vargas Ponce pidió a Ceán Bermúdez, que intercediese para que Francisco de Goya le hiciera un buen retrato ${ }^{130}$. En la carta original, escrita con un tono amistoso y divertido, se puede leer:

Quiero que lo haga Goya, á quien se le ha propuesto y ha venido en ello graciosamente. Pero quiero también y suplico á Vuestra merced le ponga una cartita diciéndole quien soy, y nuestras relaciones comunes, para que ya que esta tinaja queda colmada en la Academia, no sea con una carantoña de munición, sino como él lo hace cuando quiere ${ }^{131}$.

Existe una leyenda curiosa que explica por qué en este cuadro no aparecen dibujadas las manos de Vargas Ponce:

Cuéntase que al tratar del precio de la pintura, preguntó Goya si había de tener o no manos.

-¿Qué más da?- Contestó Vargas.

-Tan da más- replicó el primero, - que más cobro por los retratos que las tienen.

- Pues suprímanse en el mío.

Con tal condición, ideó el artista la jugarreta de reproducir al mareante amigo acariciándose el abdomen por dentro del fenomenal chaleco $\sin$ fin $(\ldots)^{132}$.

En junio de 1805, José de Vargas Ponce tuvo que ausentarse de Madrid durante un tiempo ${ }^{133}$. Casi seis meses después, estando en Pamplona, recordó que su retrato quedó terminado en casa de Francisco de Goya, por lo que pidió a la Academia que lo recogiese y que abonase la cantidad de dos mil reales vellón, precio en el que quedó acordada la ejecución del cuadro ${ }^{134}$.

${ }^{128}$ Real Academia de la Historia. Cargos académicos. [en línea]:

$<$ http://www.rah.es/laAcademia/organizacion/director1.htm> [Consulta: 2011-11-04].

${ }^{129}$ Véase acta 1805/05/10.

${ }^{130}$ Véase GP 1805/1(4).

${ }^{131}$ Véase GP 1805/1(4).

${ }^{132}$ FERNÁNDEZ DURO, Cesáreo. Correspondencia epistolar de D. José de Vargas Ponce y otros en materias de arte: Colegida por D. Cesáreo Fernández Duro y publicada por la Real Academia de Bellas Artes de San Fernando. Madrid: [s.n.], 1900. 347 p.

${ }^{133}$ Véase acta 1805/06/05.

${ }^{134}$ Véanse GP 1805/1(5) y GP 1806/1(7). 
En 1855 se solicitó la realización de una copia del retrato para que se colocase en el Ayuntamiento gaditano ${ }^{135}$, que actualmente se conserva en el Museo de las Cortes de Cádiz.

Este retrato ha estado presente en los últimos años en las exposiciones Huellas organizada por el Obispado de Cartagena y Caja Murcia en 2002; Goya en tiempos de Guerra, celebrada en el Museo Nacional del Prado en 2008; y en Floridablanca (1728 - 1808). La utopía reformadora, preparada por la Sociedad Estatal de Conmemoraciones Culturales entre septiembre de 2008 y febrero de 2009.

\section{CONCLUSIONES}

Reunir la documentación generada por una obra arte nos permite reconstruir la vida de la pieza, descubriendo nuevos datos e informaciones que pueden facilitar su estudio y conocimiento a investigadores del mundo del arte o de la historia.

$\mathrm{El}$ análisis de la documentación consultada demuestra que existe una amplia variedad de tipologías y formatos, que reflejan todos los procesos que experimenta una pieza: desde su primer encargo hasta sus restauraciones actuales. Y es que una obra de arte de interés reconocido no deja de generar documentación con el paso de los años, ya que frecuentemente es sometida a nuevos estudios, publicaciones, análisis o informes, que obligadamente originan nuevos documentos. Estas informaciones no siempre llegan a formar parte de la colección documental de la pieza, ya que cuando una obra es sometida a un estudio artístico, la publicación correspondiente no se considera material de archivo y por tanto no se incluye en su expediente.

El análisis tipológico ha dado como resultado que una obra de arte genera oficios, minutas, cartas, libramientos, recibos, informes, inventarios, notas internas, actas de sesiones, presupuestos, facturas, cesiones de derechos, seguros, correos electrónicos y documentación gráfica, además de publicaciones y estudios desde diferentes perspectivas.

En cuanto al contenido, los documentos se relacionan con las distintas fases de la vida de una obra de arte: encargo, creación de la pieza, adquisición, pagó de la obra, restauraciones, exposición, realización de copias, estudios científicos e inventarios de la institución que alberga la obra.

La utilidad de estudiar este tipo de documentación se ha visto demostrada en la reconstrucción historiográfica de las obras seleccionadas para este trabajo. Gracias a la recopilación de la documentación de la R.A.H. hemos podido conocer cómo y cuándo se gestaron estas obras, cuál era su finalidad, dónde ubicaron o de qué estudios, investigaciones o restauraciones han sido objeto. Incluso ha sido posible datar con exactitud las transcripciones de unas actas de sesiones de 1789 , que se situaban en torno a 1912, pero que realmente se corresponden con un proyecto del año 1915.

${ }^{135}$ Véase GP 1855/1(17). 
Apenas existe bibliografía sobre la Documentación aplicada al mundo del Arte. La mayoría de los estudios están realizados desde una perspectiva eminentemente museística, centrada en los documentos de gestión que la pieza artística genera en la colección. También existen repertorios bibliográficos especializados en el Arte como disciplina y tesauros y lenguajes documentales destinados a su control terminológico. Incluso en el mundo del Arte Contemporáneo, donde tanta importancia se concede a la adquisición, tratamiento y difusión de la documentación generada por las obras de arte, no se han localizado estudios teóricos que traten de manera científica cómo debe realizarse la gestión de estos fondos. Las excepciones las encontramos con las obras de Museología y documentación: criterios para la definición de un proyecto de documentación en museos $^{136}$ y la breve mención que se dedica a este tipo de documentación en Normalización documental de museos. ${ }^{137}$

Con este trabajo pretendemos demostrar que, teniendo en cuenta que vivimos en la era digital y las múltiples posibilidades que este entorno ofrece, y que cualquier investigación debe apoyarse en una documentación sólida y minuciosa, sería posible crear bases de datos destinadas a albergar expedientes ficticios abiertos, en los que se reuniera toda la documentación que una obra de arte genera durante su vida. En cada registro no sólo se incluirían las digitalizaciones de los documentos clásicos de archivo, sino que se podrían añadir reproducciones audiovisuales, referencias a publicaciones con investigaciones relacionadas y cualquier material que contribuya a reconstruir de una manera más veraz la existencia de la obra. Estos registros contribuirían de una manera indiscutible a los estudios de cualquier profesional.

Además se facilitaría el intercambio y cruce de datos entre obras del mismo autor, estilo, periodo histórico, temática similar, ubicación, exposiciones, equipos de restauración... En definitiva, valorar justamente las contribuciones positivas que la Documentación aporta a cualquier estudio científico.

Por otro lado, teniendo en cuenta la escasez de bibliografía localizada sobre la documentación en el arte, convendría desarrollar investigaciones científicas que estudiasen las implicaciones y características de este tipo de documentación, así como el hecho de que la pieza artística es un documento en si misma, que nos proporciona gran cantidad de información sobre el contexto en qué fue creada.

Como conclusión final señalaremos que la Documentación debe explorar nuevas posibilidades que se alejen del papel, para entrar en el mundo digital, con todos sus problemas y ventajas, prestando una especial importancia a los documentos gráficos y audiovisuales como testigos futuros del mundo actual. Además debe comprender y valorar adecuadamente que la obra artística en todas sus facetas, desde la pintura hasta la

\footnotetext{
${ }^{136}$ GUTIÉRREZ USILLOS (2010).

${ }^{137}$ Comisión de Normalización Documental de Museos (1998).
} 
literatura, son documentos con una gran carga informativa que deben ser tratados y estudiados desde nuestra perspectiva científica.

\section{REFERENCIAS BIBLIOGRÁFICAS}

ALFARO ASINS, Carmen; Otero MorÁn, Paloma; MARCOS Alonso, Carmen. "El Gabinete Numismático: 1711-1999". En: Tesoros del Gabinete Numismático. Las 100 mejores piezas del monetario del Museo Arqueológico Nacional. Madrid: Real Academia de la Historia, 1999. pp. 15-49.

AlmAGro-GorbeA, Martín. "Prólogo". En: MAIER, Jorge. Noticias de antigüedades de las Actas de sesiones de la Real Academia de la Historia (1792-1833). Madrid: Real Academia de la Historia, 2003. 256 p.

Almagro-GorbeA, Martín; MAIER Allende, Jorge. "La Real Academia de la Historia y la Arqueología española en el siglo XVIII". En: Congreso Internacional Iluminismo e Ilustración. Le antichitá e i suoi protagonisti in Spagna e in Italia nel XVIII secolo. Roma, 2004. pp. 1-27.

Ambourout Avaro, Anne; Guichen, Gael de. La documentación de las colecciones de los museos: ¿Por qué? ¿Cómo? [en línea]. Claudia Pettinau, trad. [s.1.]: Fundación Ilam, 2010. [ref de: 2012-03-25]. Disponible en Web: $<\mathrm{http} / / / \mathrm{www}$.iccrom.org/eng/prog_en/01coll_en/archivepreven_en/2010_02preven_guide_es.pdf $>$

ARCE, Javier: Historiografia de la Arqueología y la Historia Antigua en España (siglos XVIII-XX). Olmos, Ricardo (ed.). Madrid: Instituto de Conservación y Restauración de Bienes Culturales, 1991. 275 p.

Archivos y fondos documentales para el arte contemporáneo. [Mérida]: Consejería de Cultura y Turismo; Malpartida de Cáceres: Consorcio Museo Vostell Malpartida; Cáceres: Universidad de Extremadura D.L. 2009. 375 p.

BLANCO, Manuel. "Los archivos de arquitectura". Archivos de arquitectura: Documentos para el debate. Alcalá de Henares: Universidad de Alcalá, 2004. pp. 33-38.

BERUETE Y MORET, Aureliano de: Goya Composiciones y figuras. (Madrid, 1917. Impreso por Blass y Cia.) $176 \mathrm{p}$.

Biblioteca Virtual Miguel de Cervantes [en línea]. Catálogo. < http://www.cervantesvirtual.com/> [Consulta: 2012-25-03].

CABALlero ZoredA, Luis. "La documentación museológica". Boletín de la $A N A B A D$. 1988, tomo XXXVIII, $\mathrm{n}^{\circ} 4$. pp. 455-483.

CANTO GARCÍA, Alberto; MARTín EsCudERO, Fátima. "El hallazgo de Belalcázar (Córdoba): nuevas aportaciones". Qurtuba. 2000, nº 5. pp. 27-40.

CANTO GARCÍA, Alberto; MARTín Escudero, Fátima; Vico MonTeOliva, Jesús: Monedas Visigodas. Catálogo del Gabinete de Antigüedades de la Real Academia de la Historia. Madrid: Real Academia de la Historia, 2002. 336 p. 
CANTO García, Alberto; Rodríguez CASANOva, Isabel. Nuevos datos acerca de la inscripción califal atribuida al Castillo de Baños de la Encina (Jaén). Arqueología y Territorio Medieval. 2006, $\mathrm{n}^{\mathrm{o}}$ 13. pp. 57-66.

CIDOC: supporting museum documentation [en línea]. <http://cidoc.mediahost.org/ home $\% 28$ en\%29\%28E1\%29.xml> [Consulta: 2012-03-25].

COMISIÓN De NORMALIZACIÓN DOCUMENTAL De MuSEOS: Normalización documental de museos: elementos para una aplicación informática de gestión museográfica. Madrid: Ministerio de Educación y Cultura. Secretaría General Técnica, $1998.580 \mathrm{p}$.

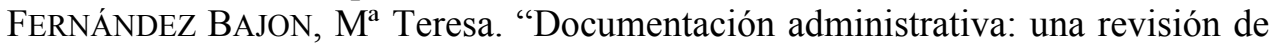
las tipologías documentales administrativas comunes". Revista general de información y documentación. 1996, vol. 6, nº 2, 1996. pp. 67-90.

FERNÁNDEZ DURO, Cesáreo: Correspondencia epistolar de D. José de Vargas Ponce y otros en materias de arte: Colegida por D. Cesáreo Fernández Duro y publicada por la Real Academia de Bellas Artes de San Fernando. Madrid: [s.n.], 1900. 347 p.

FUNDACIÓN JUAN MARCH. Biblioteca. [en línea]. <http://www.march.es/ bibliotecas/> [Consulta: 26 de marzo de 2012].

GALLEGO LORENZO, Josefa. "Estado actual de los estudios bibliográficos sobre el arte en España". Scire: representación y organización del conocimiento. 2005, vol.11, $\mathrm{n}^{\mathrm{o}} 1$, pp. 65-82.

GARCÍA MELERO, Enrique: Aproximación a una bibliografía de la pintura española. Madrid: Fundación Española Universitaria, 1978. 1188 p.

García Melero, E.; AZOrÍn LóPEZ, V.; SORLi RoJo, A. "Los repertorios bibliográficos españoles sobre las artes plásticas". Revista Española de Documentación Cientifica. 1990, vol. 13, nº 2. pp. 733-755.

GONZÁlEZ ZYMLA, Herbert; FRUTOS SASTRE, Leticia de: Archivo de la colección de pintura y escultura de la Real Academia de la Historia: Catálogo e índices. Madrid: Real Academia de la Historia, 2002. 118 p.

GonZÁlez Zymla, Herbert; Frutos SAStre, Leticia de; PÉrez SÁnchez, Alfonso E: Catálogo de pinturas de la Real Academia de la Historia. Madrid: Real Academia de la Historia, 2003. 333 p.

GoYA, Francisco de: Cartas a Martín Zapater. Mercedes Águeda, Xavier de Salas, ed. Madrid: Turner, 1982. 244 p.

GoYA, Francisco de: Diplomatario. Ángel Canellas López, ed. Zaragoza: Institución Fernando el Católico, 1981. 590 p.

GoYA, Francisco de: Diplomatario: Addenda. Ángel Canellas López, ed. Zaragoza: Institución Fernando el Católico, 1991. 40 p.

GUTIÉRREZ USILlOS, Andrés: Museología y documentación: criterios para la definición de un proyecto de documentación en museos. Gijón: Trea, 2010. 206 p. 
Junta De Andalucía. Centro de Documentación de las Artes Escénicas de Andalucia [en línea]. <http://www.juntadeandalucia.es/cultura/cdaea/> [Consulta: 25 de marzo de 2012].

LORENZO CADARSO, Pedro Luis; VIVAS MORENO, Agustín: Lecciones de archivistica general y documentación del patrimonio histórico. [Cáceres]: Universidad de Extremadura, Instituto de Ciencias de la Educación: Abecedario, 2004. 455 p.

MAIER, Jorge. "La Comisión de Antigüedades de la Real Academia de la Historia". $3^{\circ}$ Congresso de Arqueologia Peninsular. Vol 1. Arqueología peninsular. História, teoria e prática. Porto, 2000. pp. 213-236.

MAIER, Jorge. "II Centenario de la Real Cédula de 1803. La Real Academia de la Historia y el inicio de la legislación sobre el Patrimonio Arqueológico y Monumental en España”. Boletín de la Real Academia de la Historia. Madrid, 2003. pp. 439-473.

MAIER, Jorge: Noticias de Antigüedades de las Actas de Sesiones de la R.A.H. (1792-1833). Madrid: Real Academia de la Historia, 2003. 256 p.

MAIER, Jorge: Noticias de Antigüedades de las Actas de Sesiones de la R.A.H. (1834-1874). Madrid: Real Academia de la Historia, 2008. 406 p.

MAIER, Jorge: Noticias de Antigüedades de las Actas de Sesiones de la R.A.H. (1738-1791). Madrid: Real Academia de la Historia, 2011. 484 p.

Manual de documentos administrativos. Madrid: Tecnos: Ministerio de las Administraciones Públicas, 2003. 349 p.

Manual de registro y documentación de bienes culturales. Lina Ángel Vega, ed. Santiago de Chile: CDPB, 2008. 142 p.

MARÍN TORRES, María Teresa. "La documentación museográfica en el Reino Unido: tendencias actuales". Imafronte. 1998-1999, n 14. pp. 141-154.

MARTín ESCUDERO, Fátima. "Sobre el hallazgo de dinares del Hospital Militar de Zaragoza (1858)". Actas XI Congreso Nacional de Numismática. Zaragoza 1619 de Octubre de 2002. Zaragoza, 2003. pp. 257-268.

MARTÍN ESCUDERO, Fátima. "El primer proyecto de publicación de un catálogo de moneda andalusí en España: Discurso y Tablas de Medallas Árabes de Miguel de Casiri”. Documenta \& Instrumenta, 8. Madrid, 2010. pp.145-180.

MARTín Escudero, Fátima; CANTO GARCÍA, Alberto; CEPAS, Adela. Archivo del Gabinete Numario: Catálogo e indices. Madrid: Real Academia de la Historia, 2004. 464 p.

MARTínEZ NúÑEZ, Ma Antonia; RODRÍGUEZ CASANOVA, Isabel; CANTO GARCíA, Alberto: Epigrafía árabe. Catálogo del Gabinete de Antigüedades. Real Academia de la Historia. Madrid, 2007. 397 p.

Ministerio De Educación, Cultura Y Deporte. Catálogo Colectivo del Patrimonio Bibliográfico Español [en línea]. <http://www.mcu.es/bibliotecas/ MC/CCPB/index.html> [Consulta: 2012-03-25].

MORA, Gloria: Historias de Mármol. La Arqueología clásica española en el siglo XVIII. Anejos de Archivo Español de Arqueología, XVIII. Madrid, 1998. 164 p. 
Ministerio De Educación, Cultura Y Deporte. "Origen de los estudios numismáticos en España: el manuscrito perdido de Felipe de Guevara y otros tratados del siglo XVI". XIII Congreso Internacional de Numismática. Madrid2003. Actas. Tomo I. Madrid, 2005. pp. 77-83.

Ministerio De Educación, Cultura Y Deporte. "Coleccionistas españoles en Italia. El monetario de Dámaso Puertas, médico del XIV Duque de Alba". Arqueología, Coleccionismo y Antigüedad. España e Italia en el siglo XIX. José Beltrán, Beatrice Cacciotti y Beatrice Palma (eds.). Sevilla, 2007. pp. 435-458.

MUÑOZ JiMÉNEZ, José Miguel. "El protocolo notarial como fuente para la historia del arte". La investigación y las fuentes documentales de los Archivos. Guadalajara: ANABAD, 1996. Tomo I, pp. 391-398.

Ministerio De EdUCACión, Cultura Y Deporte. Archivo Central del Ministerio de Cultura [en línea]. <http://www.mcu.es/archivos/MC/AMC/ FondosDocumentales/Introduccion.html $>$ [Consulta: 2012-03-25].

MUSEO DEL PRADO [en línea]. Enciclopedia online. $<\mathrm{http} / / \mathrm{www}$. museodelprado.es/enciclopedia/enciclopedia-on-line/> [Consulta: 2012-03-25].

PÉREZ De GUZMÁN Y GALLO, Juan. "Retratos y bustos de la Real Academia de la Historia". Boletín de la Real Academia de la Historia. 1917, tomo LXX. pp. 189-195.

ReAl ACADEMIA De LA Historia [en línea]. <http://www.rah.es/index.htm> [Consulta: 2012-03-25]

PÉREZ De GuZMÁN Y GALlo, Juan. Base de datos del Centro de Estudios Biográficos [en línea]. <http://www.rah.es:8888/ArchiDocWeb-RAH/action/buscarElementos? method=buscar\&tipoBusqueda $=6 \&$ letra $=\mathrm{A}>$ [Consulta: 2012-03-25].

PÉrez De GuZMÁn Y Gallo, Juan: Tesoros de la Real Academia de la Historia: Exposición celebrada en el Palacio Real de Madrid. Abril-Junio, 2001. Madrid: Real Academia de la Historia: Patrimonio Nacional, 2001. 384 p.

RED NACIONAL DE Museos. Guía para el inventario, catalogación y documentación de colecciones de museos. Bogotá: Ministerio de Cultura: Museo Nacional de Colombia, 2004. 104 p.

Ruiz CABriadA, Agustín. Aportación a una bibliografía de Goya. Madrid: Junta Técnica de Archivos, Bibliotecas y Museos, 1946. 198 p.

Salas Álvarez, Jesús de la Ascensión: La arqueología en Andalucía durante la Ilustración (1736-1808). Málaga-Sevilla, 2010. 377 p.

SÁNCHEZ PRIETO, Ana Belén. "Documentos administrativos: un ensayo de diplomática contemporánea". Documentación de las ciencias de la información. 1995, $\mathrm{n}^{\circ}$ 18. pp. 193-210.

SEONE, Marqués de. "Correspondencia epistolar entre don José Vargas Ponce y don Juan Agustín Ceán Bermúdez durante los años 1803 a 1805, existente en los archivos de la Dirección de Hidrografía y de la Real Academia de Historia”. 
Boletín de la Real Academia de la Historia. Julio-septiembre, 1905, tomo XLVII, cuadernos I-III, pp. 5-60 138 .

VALVERDE MADRID, Jesús. "El cuadro de San Eulogio, de Agustín Grande, en el Seminario de Córdoba". Córdoba: Boletín de la Real Academia. 1964, pp. 368-404.

${ }^{138}$ Este documento se encuentra también digitalizado en la Biblioteca Virtual Miguel de Cervantes [ref. 2012-03-25]: <http://descargas.cervantesvirtual.com/servlet/SirveObras/ 24671175902139940700080/025286.pdf> 